Article

\title{
Complementary Cooperation of Dual Power Circuits to Drive Active Magnetic Bearings
}

\author{
Hsin-Lin Chiu and Nan-Chyuan Tsai * \\ Department of Mechanical Engineering, National Cheng Kung University; Tainan 70101, Taiwan; \\ n18001224@mail.ncku.edu.tw \\ * Correspondence: nortren@mail.ncku.edu.tw; Tel.: +886-6275-7575 (ext. 62137)
}

Received: 18 May 2018; Accepted: 25 July 2018; Published: 31 July 2018

\begin{abstract}
A compact-design hybrid power amplifier for AMB (active magnetic bearing) units, named as dual cooperative drive circuit $\left(\mathrm{DC}^{2}\right)$, is designed and verified by intensive experiments. $\mathrm{DC}^{2}$ can operate under dual mode: either digital driving mode (DDM) or analog driving mode (ADM). By taking advantages of the complementary cooperation between DDM and ADM, the proposed $D^{2}$ manifests its superiorities mainly in three aspects: (i) Compared to a traditional 2-level PWM (pulse width modulation) drive circuit, the improvement degree of reducing the amplitudes of current ripples is up to $62 \%$. (ii) By taking advantages of mutually complementary cooperation between DDM and ADM, the steady-state errors of output current, which is exerted to the coils of AMBs, can be much reduced by $\mathrm{DC}^{2}$. (iii) $\mathrm{DC}^{2}$ can provide a high-current slew rate so that the response of AMBs is fast and quick enough to regulate the high-speed rotor back to the neutral position within a very short time period below $0.40 \mathrm{~ms}$. In addition, the proposed $D^{2}$ is particularly suitable to be compliant with digital controllers and DSPs (digital signal processors) since the commands or drive sequences are all in DC (direct current) manner.
\end{abstract}

Keywords: active magnetic bearing; rotor position regulation; drive circuit; pulse width modulation

\section{Introduction}

Active magnetic bearings (AMBs) are able to levitate the interested objects in a fashion of no friction and no mechanical wear. Therefore, they are increasingly applied to the industries for which high speed and high precision are both required, such as high-speed compressors, turbo-machineries, high-precision machine tools, and flywheel energy storage systems. One of the most important components of a superior AMB unit is its drive circuit. Most of the drive circuits applied to AMBs are of analog type [1,2]. Analog drive circuits possess the merits of high linearity and low electromagnetic interference (EMI). However, the energy efficiency of analog drive circuits is inherently poor because a great percentage of the energy power is converted into heat at the corresponding driver integrated circuits (ICs). By contrast, the power loss is relatively limited for the digital drive circuits. As a consequence, a large number of studies on digital drive circuits for AMBs were proposed during the past decades [3-9]. The main shortcoming of digital drive circuits to AMBs is: severe current ripple induced. The most popular technique for current ripple reduction is the so called three-level pulse width modulation (PWM) scheme $[8,9]$. Nevertheless, the current ripple problem by digital drive circuits is still more serious than that by analog drive circuits.

Due to analog drive circuits and digital drive circuits having their own irreplaceable advantages, many types of switch-linear hybrid (SLH) power amplifiers were proposed recently [10-14]. The SLH amplifier is mainly composed by a set of linear power amplifier and a set of two-level switching power supply. However, the switching frequency of the power supply has to be much higher than the bandwidth of the linear power amplifier. As well known, high switching frequency results in serious 
switching loss [11]. Therefore, a multilevel voltage supply, namely a multilevel converter, is proposed to replace the two-level switching power supply to improve the overall energy efficiency [11-14]. Unfortunately, "multilevel" implies it requires a large number of electronic components. The reliability of the overall drive circuit would be accordingly reduced. Besides, the more complex the circuit, the larger the impact of time delay which certainly downgrades the quality of rotor dynamic control. To overcome the aforementioned shortcomings, a compact-design hybrid power amplifier for AMB units, named as dual cooperative drive circuit $\left(D C^{2}\right)$, is proposed by this paper. The proposed $D C^{2}$ is able to conduct under dual operation modes: digital driving mode (DDM) and analog driving mode (ADM). Taking advantage of the complementary characteristics of interchange between DDM and $\mathrm{ADM}$, the proposed $\mathrm{DC}^{2}$ manifests its superiorities on structure compactness, high energy efficiency, fast response, low tracking error and fairly mild current ripples. This work is absolutely aimed at drive circuit design. Regarding AMB position control on high-speed rotors, please refer to the previous works of the authors [15-17].

\section{Design of Dual Cooperative Drive Circuit $\left(\mathrm{DC}^{2}\right)$}

The conceptual design of the proposed drive circuit stems from the two-quadrant H-bridge drive circuit [18]. That is, only positive coil current is provided. The configuration of the proposed dual cooperative drive circuit $\left(\mathrm{DC}^{2}\right)$ for $\mathrm{AMB}$ is shown in Figure 1. Compared with the H-bridge drive circuit, merely two essential electronic components, i.e., a digital to analog converter (DAC) and an analog multiplexer (analog MUX) are additionally included by $D^{2}$. The chip codes of the applied DAC and the applied analog MUX are LTC2644 and MAX4519 respectively. Their corresponding failure rates are 5.30 [19] and 3.42 [20] FITs (FIT: one failure in one billion hour) respectively at $55^{\circ} \mathrm{C}$ with a $60 \%$ confidence level. Basically, $\mathrm{DC}^{2}$ can operate under dual modes: digital driving mode (DDM) and analog driving mode (ADM).

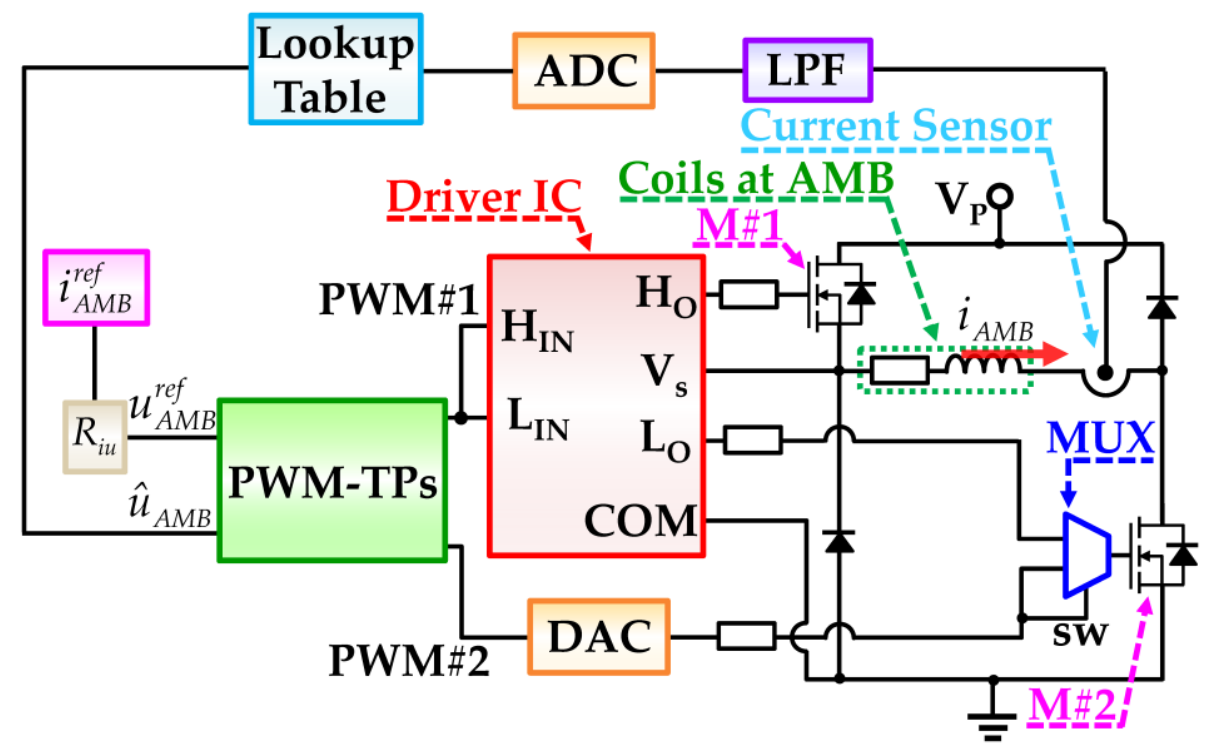

Figure 1. Circuit configuration of $\mathrm{DC}^{2}$ (dual cooperative drive circuit).

\subsection{Digital Drive Mode (DDM)}

From the viewpoint of signal processing, the corresponding circuit under DDM is nothing but a switching power amplifier. The operation states of the switching power amplifier are illustrated in Figure 2. Under DDM, solely one PWM signal, $P W M \# 1$, is required to synchronously switch on/off

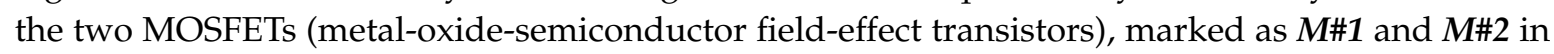
Figure 1. When the two MOSFETs are turned on, shown in Figure 2a, the switching power amplifier operates at charge state. On the other hand, as the two MOSFETs are both turned off, shown in 
Figure $2 b$, the power amplifier is at discharge state. Under DDM, the two MOSFETs are switched on/off synchronously so that the output current is able to track the desired output as fast as possible. Accordingly, AMBs can adjust the levitation force promptly against the external disturbance to the rotor. That is, DDM is suitable to be applied for the transient state of the rotor/AMB dynamics. As the rotor/AMB dynamics is at steady state, instead, ADM takes over to provide a relatively stable levitation force to the rotor, with a relatively mild ripple effect that makes the rotor wobble reciprocally.

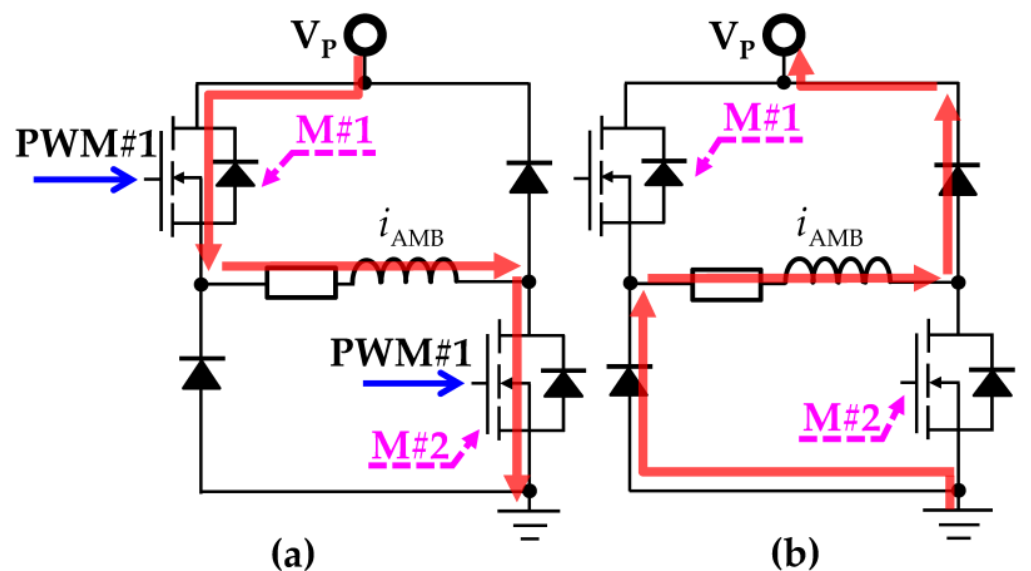

Figure 2. Operation states of $\mathrm{DC}^{2}$ (dual cooperative drive circuit) under DDM (digital driving mode): (a) charge state; (b) discharge state.

\subsection{Analog Drive Mode (ADM)}

The corresponding operation states under ADM are depicted in Figure 3. PWM\#1 is applied to adjust the drain-source voltage of $M \# 2$, while $P W M \# 2$ is utilized to regulate the AMB coil current. Under ADM, $M \# 2$ always operates within saturation region so that its characteristics can be analogous to a voltage-controlled power transducer. As long as the MOSFET operates within its saturation region, the output current is strongly dependent of the gate-source voltage, $V_{G S}$. Accordingly, the digital control sequence to adjust the output current of $\mathrm{DC}^{2}$, i.e., $P W M \# 2$, is converted into analog fashion via

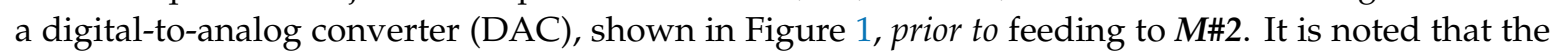

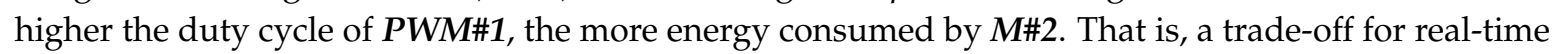

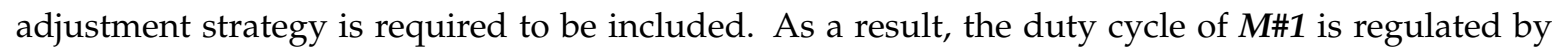
PWM\#1 to minimize, to some extent, the energy consumption by $\mathbf{M} \# 2$.

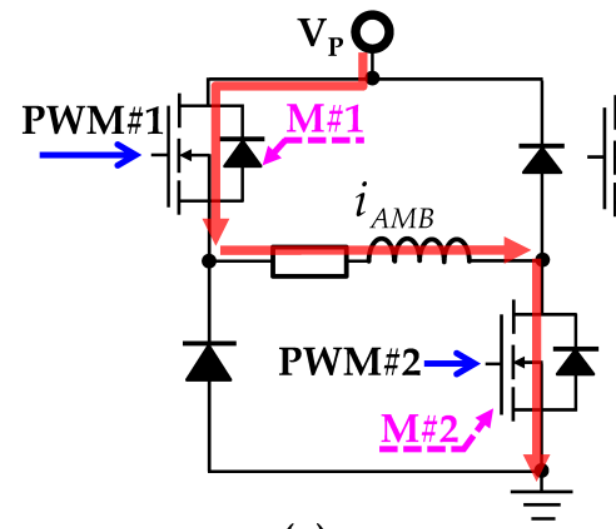

(a)

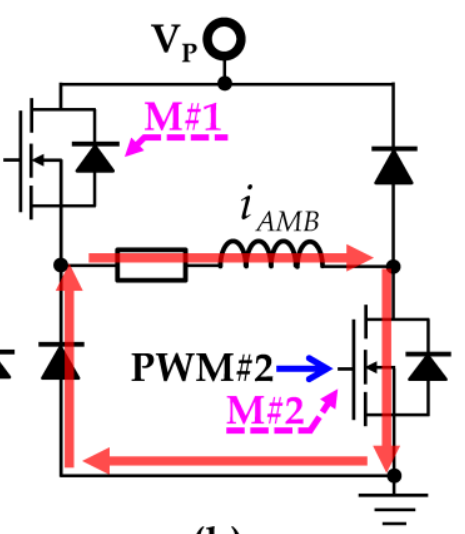

(b)

Figure 3. Operation states of $\mathrm{DC}^{2}$ (dual cooperative drive circuit) under ADM (analog driving mode): (a) charge state; (b) discharge state. 


\section{Pulse Width Modulation-Tuning Processors (PWM-TPs)}

Since $\mathrm{DC}^{2}$ conducts under two distinct operation modes, i.e., DDM and ADM, two pulse width modulation-tuning processors (PWM-TPs) are required to appropriately tune the output current to the AMB unit. In addition, a switch is applied to determine the timing of change between these two modes, i.e., DDM and ADM. The schematic diagram for the PWM-TPs of $D C^{2}$ is shown in Figure 4. $i_{A M B}^{r e f}$ is the desired current applied to the AMB coils while $u_{A M B}^{r e f}$ is the corresponding voltage command. On the other hand, $i_{A M B}$ is the actual current at the AMB coils, and $\hat{u}_{A M B}$ is the converted voltage with respect to the measured current by the equipped current sensor (CS) upon $i_{A M B}$. If the error between $u_{A M B}^{r e f}$ and $\hat{u}_{A M B}$ is significant, $\mathrm{DC}^{2}$ operates under DDM so that the output current by $\mathrm{DC}^{2}, \hat{u}_{A M B}$, can quickly catch up the desired quantity, $u_{A M B}^{r e f}$. On the contrary, once the output current gets close to the desired quantity, $\mathrm{DC}^{2}$ operates under ADM to generate a relatively stable current. The design procedure of PWM-TPs is shown in Figure 5.

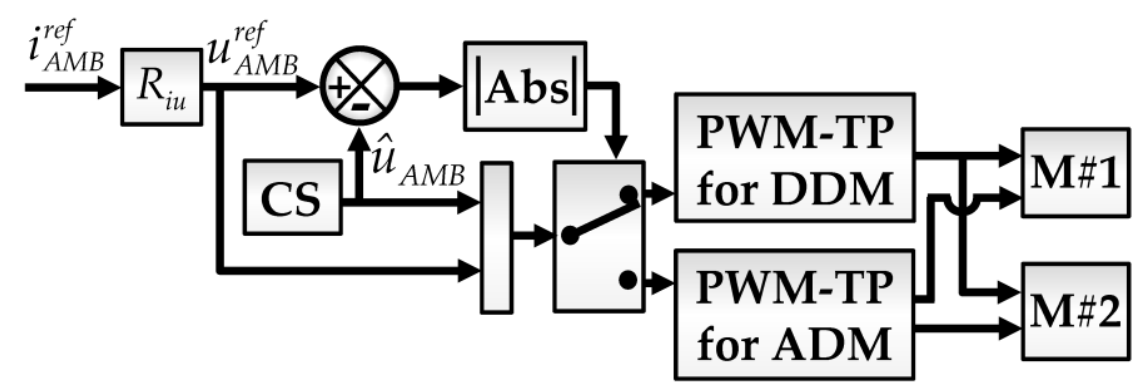

Figure 4. Schematic diagram for two PWM-TPs (pulse width modulation-tuning processors) embedded in $\mathrm{DC}^{2}$ (dual cooperative drive circuit).

The steps to determine the PI gains for DDM and ADM are described by Remark\#1 and Remark\#2 respectively as follows:

Remark 1. The steps to tune the PI gains for DDM

Step 1 Based on the step-wise reference shown in Section 4, the gain, $K_{P}$, with respect to proportional action at PI controller is tuned from zero to infinity.

Step 2 As $K_{P}$ is tuned from zero to $K_{P}^{*}=300$, the steady-state errors are all decreased gradually. By contrast, as $K_{P}$ is tuned from $K_{P}^{*}$ to infinity, the corresponding steady-state errors are all increased gradually.

Step 3 It is concluded that $K_{P}^{*}=300$ is the gain finally chosen.

Step 4 Secondly, the gain, $K_{I}$, with respect to the integral action at PI controller is tuned from zero to infinity.

Step 5 It is observed that the steady-state errors are altered from negative values to positive values as $K_{I}$ from zero to infinity while $K_{P}^{*}=300$ is fixed. Therefore, $K_{I}^{*}=1000$ is chosen since the corresponding steady-state errors are approximated to zero.

Remark 2. The steps to tune the PI gains for $A D M$

Step 1 Based on the step-wise reference shown in Section 4, the gain, $K_{P}$, with respect to proportional action at PI controller is tuned from zero to infinity.

Step 2 As $K_{P}$ is tuned from zero to $\hat{K}_{P}=100$, the steady-state errors are all decreased gradually. By contrast, as $K_{P}$ is tuned from $\hat{K}_{P}$ to infinity, the corresponding steady-state errors are all increased gradually. 
Step 3 Different from the DDM, as $\hat{K}_{P} \geq 95$, the tracking errors of output current would be more than the threshold such that ADM is cut off and then switched to DDM. In this case, we finally choose $K_{P}^{*}=90$ to prevent any potential switch to DDM.

Step 4 Secondly, the gain, $K_{I}$, with respect to the integral action at PI controller is tuned from zero to infinity.

Step 5 It is observed that the steady-state errors are altered from negative values to positive values as $K_{I}$ from zero to infinity while $K_{P}^{*}=90$ is fixed. Therefore, $K_{I}^{*}=300$ is chosen since the corresponding steady-state errors are approximated to zero.

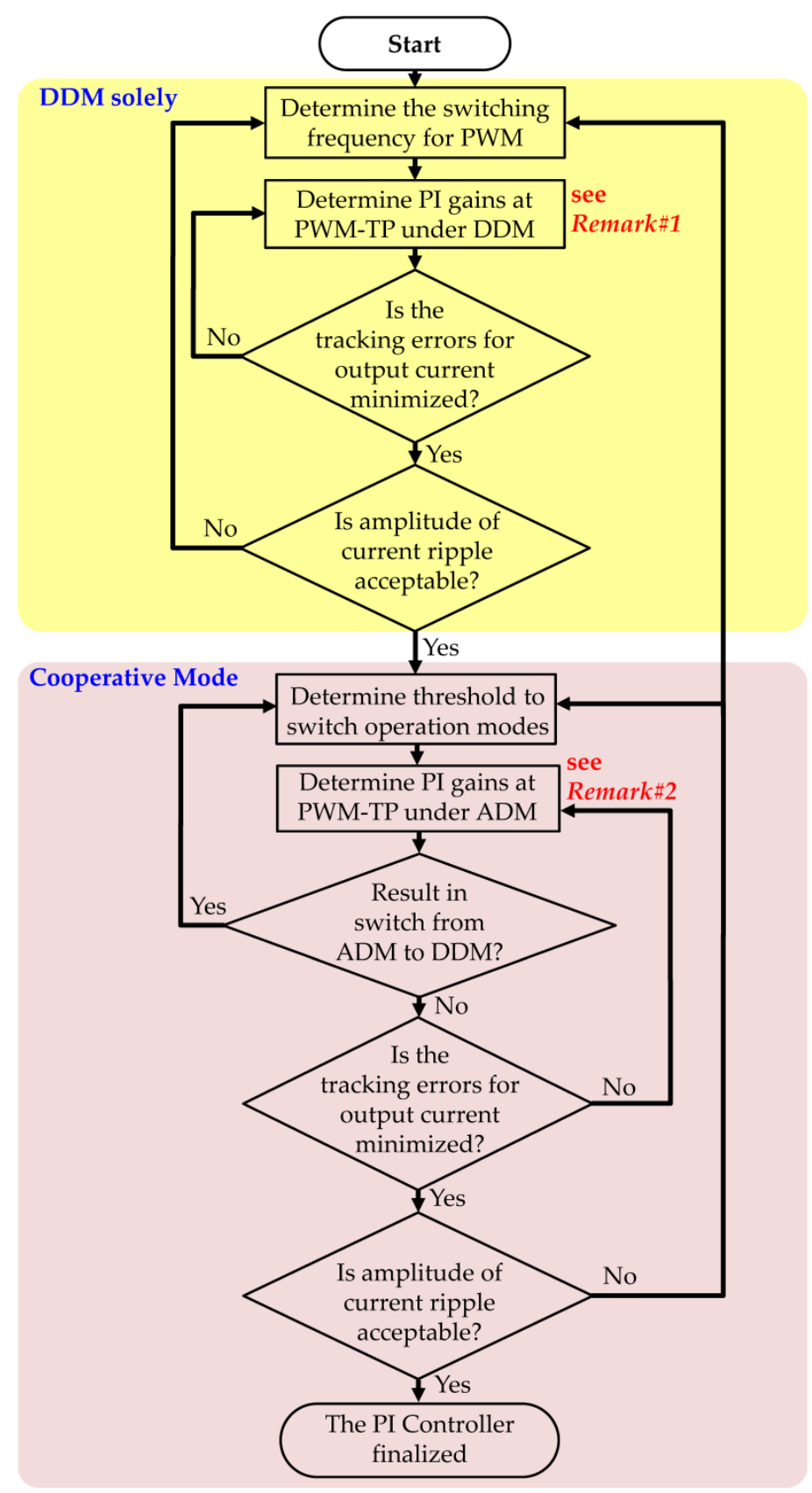

Figure 5. Design procedure of PWM-TPs (pulse width modulation-tuning processors). 


\subsection{PWM-TP for DDM}

One of the major merits of $\mathrm{DC}^{2}$ under DDM is: relatively high current slew rate of output current. In other words, DDM is suitable to be employed to the transient state of rotor/AMB dynamics. For there always exists high-frequency current ripples under DDM, the derivative action of a PID (Proportional-Integral-Derivative) controller would certainly downgrade the quality of output current. Therefore, instead a PI (Proportional-Integral) controller, shown in Figure 6, is employed to tune the duty ratio of $P W M \# 1$.

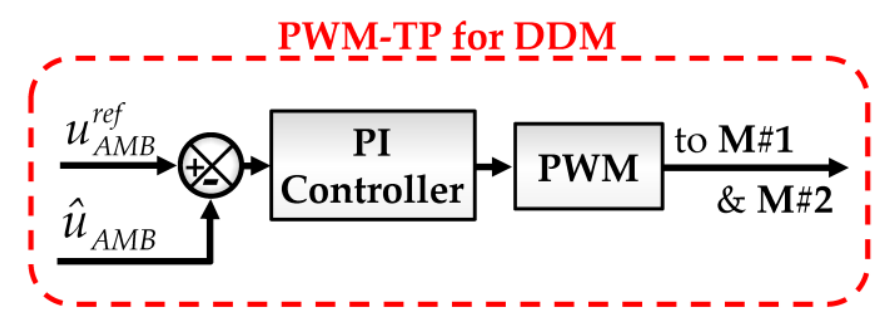

Figure 6. Schematic diagram for PWM-TP (pulse width modulation-tuning processors) under DDM (digital driving mode).

\subsection{PWM-TP for ADM}

Owing to one of the main shortcomings of DDM: inevitable fluctuation of the supplied voltage downgrades the quality of the output current to AMB coils, another operation mode, i.e., ADM, is joined to provide a relatively stable output current to regulate the steady state of rotor position. Under ADM, M\#2 operates, within saturation region, to work like a voltage-controlled power transistor. The schematic diagram for PWM-TP under ADM is depicted in Figure 7. Within the PWM-TP under ADM, a low pass filter (LPF) is employed to eliminate the current ripples lurked in the feedback signal. As a consequence, the degree of fluctuation of the feedback signal is much decreased from "intermediate level" down to "mild or low level". Afterwards, the error between $u_{A M B}$ and $\hat{u}_{A M B}$ is fed to a PI controller to adjust the desired output current precisely. In addition, this error is also applied for fine-tuning the duty ratio of $P W M \# \mathbf{1}$ such that the energy consumption can be reduced. Furthermore, there are two compensators, i.e., $K_{b}^{V}$ and $K_{b}^{I}$ shown in Figure 6, are included to adjust the duty ratios of $P W M \# 1$ and $P W M \# 2$ respectively.

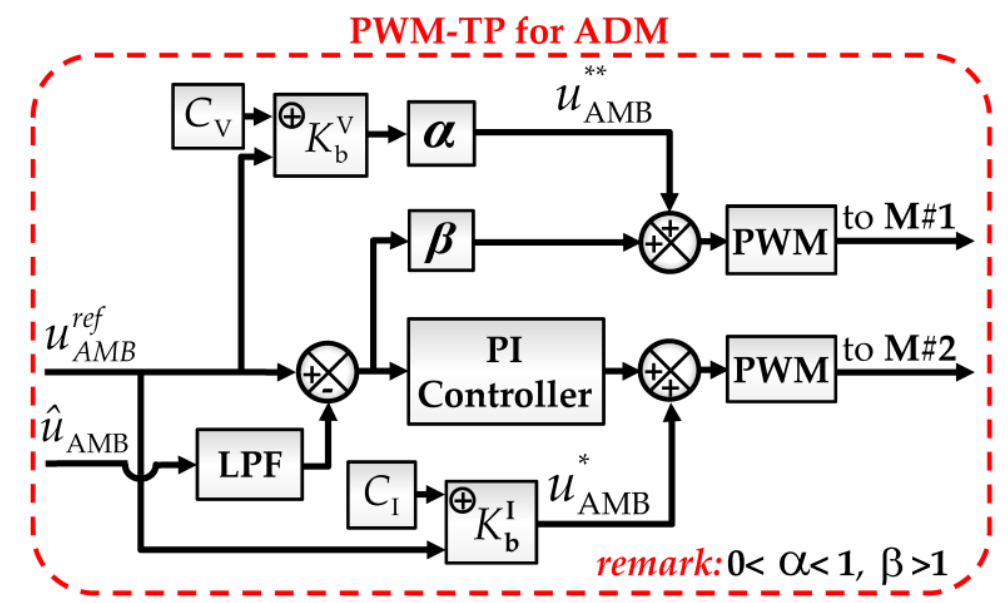

Figure 7. Schematic diagram for PWM-TP (pulse width modulation-tuning processors) under ADM (analog driving mode). 


\section{Simulations}

In this section, intensive simulations, via MATLAB/Simulink, for PWM-TPs to track the desired output are undertaken to verify the feasibility and efficacy of $D C^{2}$. The Simulink model of $D C^{2}$ is depicted in Figure 8. The corresponding environmental setup for the simulations undertaken later is listed in Table 1. The reference signal to track, i.e., the desired output, is a step-wise function while the applied voltage to drive the AMB coil, $V_{P}$, is set as 40 VDC. $i_{A M B}^{r e f}$ is the desired current applied to the AMB coils while $u_{A M B}^{r e f}$ is the corresponding voltage command. The constant resistance with respect to $u_{A M B}^{r e f}$ over $i_{A M B}^{r e f}$, i.e., $R_{i u}$ in Figure 5 , is set as $1 \Omega$. On the other hand, $i_{A M B}$ is the actual current at the AMB coils, and $\hat{u}_{A M B}$ is the converted voltage with respect to the measured current by the equipped current sensor (CS) upon $i_{A M B}$. The constant resistance for $i_{A M B}$ converted to $\hat{u}_{A M B}$ is set as $1 \Omega$. In addition, a switch is applied to determine the timing of change between these two modes, i.e., DDM and ADM. As long as the error between $i_{A M B}$ and $i_{A M B}^{r e f}$ is over $0.03 \mathrm{~A}$, then $\mathrm{DC}^{2}$ is controlled by PWM-TP under DDM. On the contrary, as the error between $i_{A M B}$ and $i_{A M B}^{r e f}$ is less than or equal to $0.03 \mathrm{~A}$, then $\mathrm{DC}^{2}$ is controlled by PWM-TP under ADM.

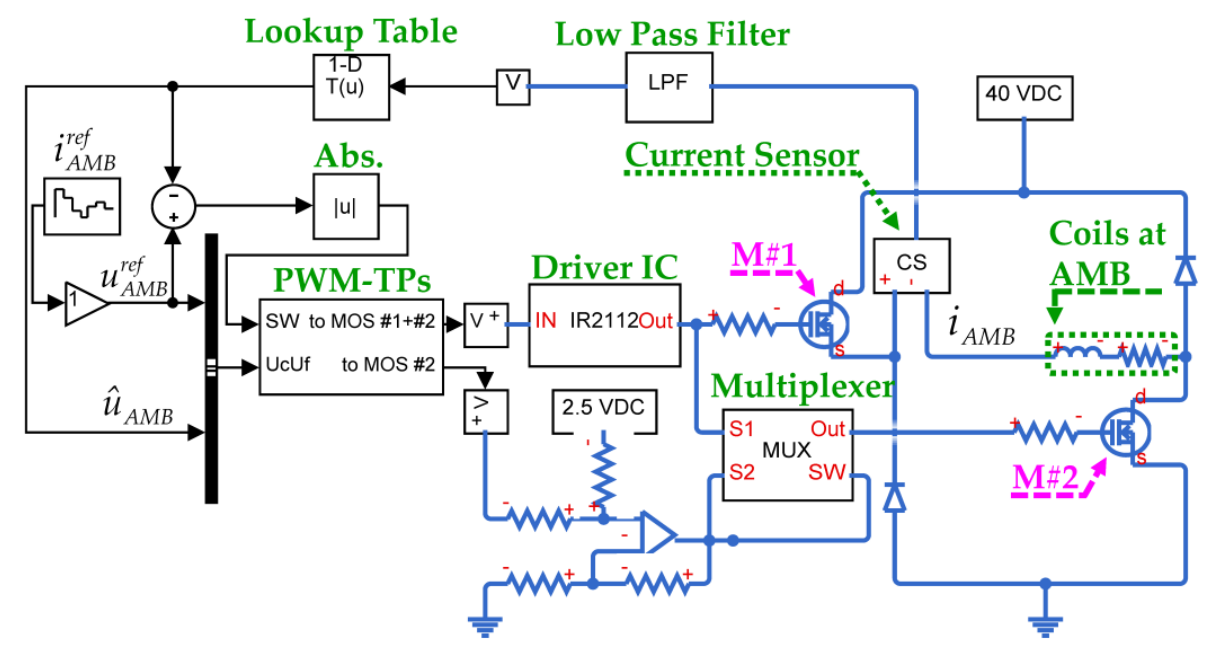

Figure 8. Simulink model of $\mathrm{DC}^{2}$ (dual cooperative drive circuit).

Table 1. Environmental setup of simulations.

\begin{tabular}{ll}
\hline \multicolumn{1}{c}{ Parameters } & \multicolumn{1}{c}{ Value } \\
\hline Solver Type & Variable-step \\
Numerical Method & ode23t \\
Supply Voltage to AMB & $40 \mathrm{VDC}$ \\
PWM Switching Frequency & $22 \mathrm{kHz}$ \\
Threshold to Switch Operation Mode & $0.03 \mathrm{~V}$ \\
Threshold of Multiplexer & $3.005 \mathrm{~V}$ \\
Gate-source threshold voltage of MOSFET & $3 \mathrm{~V}$ \\
Drain-source on Resistance of MOSFET & $0.028 \Omega$ \\
Channel Modulation of MOSFET & $0.01 \mathrm{~V}^{-1}$ \\
Gate-source voltage for R_DS (on) & $10 \mathrm{~V}$ \\
Drain current for R_DS (on) & $75 \mathrm{~A}$ \\
Transresistance of Current Sensor & $1 \Omega$ \\
P Gain of PWM-TP under DDM & 300 \\
I Gain of PWM-TP under DDM & 1000 \\
P Gain of PWM-TP under ADM & 90 \\
I Gain of PWM-TP under ADM & 300 \\
Resistance of AMB coil & $0.9 \Omega$ \\
Inductance of AMB coil & $13 \mathrm{mH}$ \\
\hline
\end{tabular}


The desired output, i.e., $i_{A M B}^{r e f}$ shown in Figure 8, to be tracked is nothing but a sequence of step-wise signal whose quantity in ampare is limited by [0, $1.5 \mathrm{~A}]$. The time duration of each step is set as $5 \mathrm{~ms}$. The output currents and the tracking errors with respect to output current by two-state Power Amplifier (PA), i.e., DDM, three-state PA, $\mathrm{DC}^{2}$ and ADM, are shown in Figure 9. Unfortunately, the peak-to-peak amplitudes of current ripples under DDM are up to $30 \mathrm{~mA}$. Since the current ripples are too severe so that the regulation performance of AMB upon the position deviation of rotor is much downgraded, the other operation mode, namely ADM, has to be joined to reduce the aforesaid current ripples. It is noted that, under ADM, $\mathbf{M \# 2}$ is ensured to operate in saturation region. As $\mathbf{M \# 2}$ operates in its saturation region, the higher the gate-source voltage, $V_{G S}$, the steeper the slope of the curve of $i_{D}$ versus $V_{D S}$. Therefore, under $\mathrm{ADM}$, once $V_{D S}$ of $M \# 2$ is altered during a very short time interval which is taken by the on-off action of $\mathbf{M \# 1}$, the lower $i_{D}$ is induced, the minor current ripple would be carried by the resulted output current. From the simulation results under ADM, when $i_{A M B}$ is $1.5 \mathrm{~A}$, the amplitude of current ripples is about $7.2 \mathrm{~mA}$. Moreover, the amplitude of current ripples is down to $2.1 \mathrm{~mA}$ as $i_{A M B}$ is reduced to $0.01 \mathrm{~A}$. On the other hand, it can be observed that steady-state errors are within $[-10 \mathrm{~mA},+5 \mathrm{~mA}]$ under DDM. In comparison, the steady-state errors are, all the time, within the range $[0,+8 \mathrm{~mA}]$ under ADM. This range is about half of that under DDM. Besides, it is obvious that there are a few spikes induced at three-state PA while no any spikes at $\mathrm{DC}^{2}$.

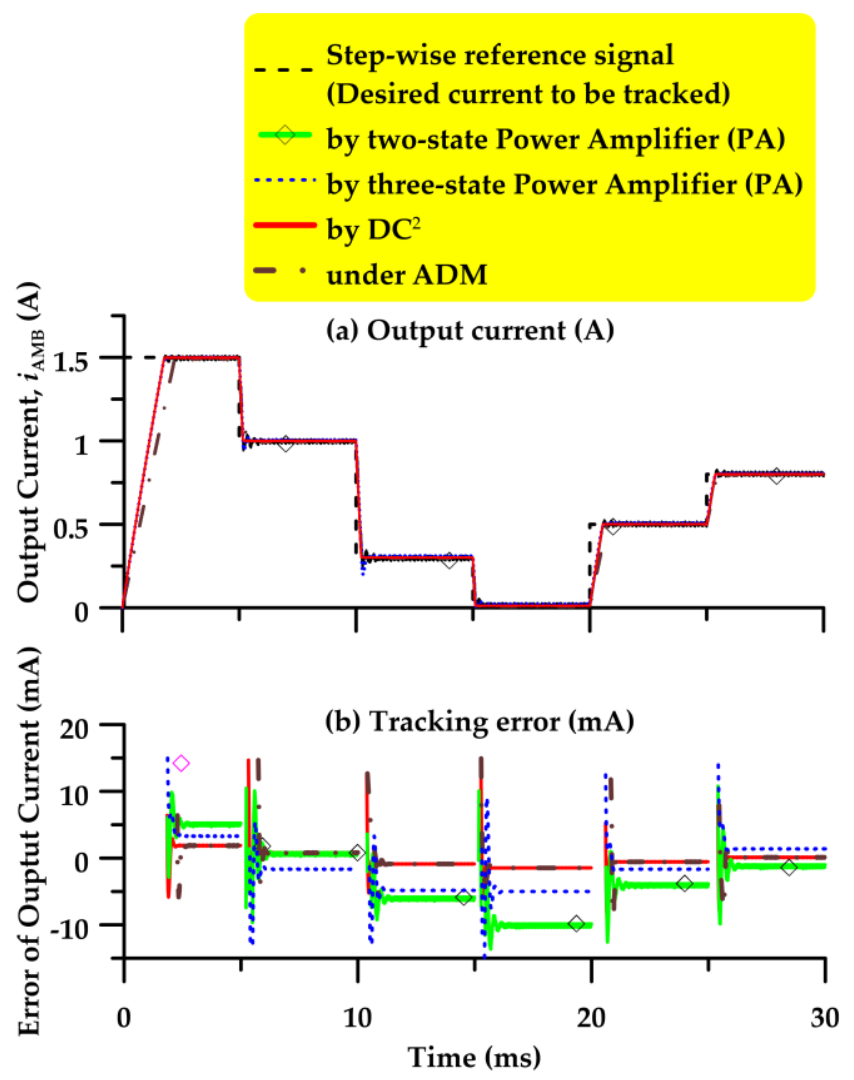

Figure 9. Output currents and tracking errors by three-state PA (power amplifier), DDM (digital driving mode), ADM (analog driving mode) and $\mathrm{DC}^{2}$ (dual cooperative drive circuit).

Since DDM and ADM possess their own particular merits, DDM and ADM are combined together to constitute the proposed $\mathrm{DC}^{2}$. As a matter of fact, taking advantage of joint DDM and ADM, the tracking of $\mathrm{DC}^{2}$ can be further reduced to be within [-1.5 mA, $\left.+2 \mathrm{~mA}\right]$. To be more explicitly compared, the tracking errors (TEs) by two-state power amplifier (PA), three-state PA and $\mathrm{DC}^{2}$ are summarized in Table 2. As the applied current to AMB coils, $i_{A M B}$, is $0.01 \mathrm{~A}$, the tracking error by $\mathrm{DC}^{2}$ is below $15 \%$ while the tracking error by two-state PA is up to $133.6 \%$. As $i_{A M B}$ is much greater 
than $0.01 \mathrm{~A}$, the tracking by $\mathrm{DC}^{2}$ is reduced to $0.3 \%$ or below. On the other hand, the comparison, in terms of the peak-to-peak amplitude of current ripple (PPACR), by a two-state PA, three-state PA and $\mathrm{DC}^{2}$ is concluded by Table 3 . During the $\mathrm{k}^{\text {th }}$ time interval, PPACR is defined as the difference between $\max \left\{i_{A M B}(t),(k-1) T_{S}<t \leq k T_{S}\right\}$ and $\min \left\{i_{A M B}(t),(k-1) T_{S}<t \leq k T_{S}\right\}$ where $k \in N$, $T_{S}$ is the time period and $i_{A M B}(t)$ the actual current applied to coils at AMB. The current ripples by two-state PA are over $27 \mathrm{~mA}$. Compared with two-state PA, the improvement degree of reducing peak-to-peak amplitude of current ripples by $\mathrm{DC}^{2}$ is up to $94 \%$ as $i_{A M B}$ is by $0.01 \mathrm{~A}$, i.e., low drive current, under steady-state circumstance. On the contrary, as $i_{A M B}$ is by $1.5 \mathrm{~A}$, i.e., high drive current, under transient-state circumstance, the improvement degree of reducing the peak-to-peak amplitude of current ripples by $\mathrm{DC}^{2}$ is about $74 \%$. Besides, the power dissipations at MOSFETs by two-state PA, three-state PA and $\mathrm{DC}^{2}$ are summarized in Table 4 . The power dissipation at MOSFETs is mainly determined by the applied current, on-resistance of MOSFET and the time duration at on-state, i.e., duty cycle. It is noted that the duty cycle under ADM are normally below $20 \%$ while it is usually above 75\% under DDM. Therefore, though the on-resistance of $\mathbf{M} \# \mathbf{2}$ under ADM is about twice of that under DDM, the power dissipation at $\mathbf{M} \# \mathbf{2}$ under ADM is still lower than that under DDM. To sum up, owing to the mutually complementary cooperation between DDM and ADM, the proposed $\mathrm{DC}^{2}$ at least has three outstanding advantages such as: (i) the slew rate of output current is high, (ii) the tracking errors can be greatly reduced, and (iii) the current ripples are significantly suppressed.

Table 2. Tracking errors on $i_{A M B}$.

\begin{tabular}{|c|c|c|c|c|c|c|}
\hline \multirow[b]{2}{*}{ A: Amplitude of $i_{A M B}(\mathrm{~A})$} & \multicolumn{2}{|c|}{ Two-State PA (DDM) } & \multicolumn{2}{|c|}{ Three-State PA } & \multicolumn{2}{|c|}{$\mathrm{DC}^{2}$} \\
\hline & $\begin{array}{l}\text { B: TE } \\
(\mathrm{mA})\end{array}$ & $\begin{array}{c}\text { C: Error } \\
\mathrm{C}=\mathrm{B} / \mathrm{A}(\%)\end{array}$ & $\begin{array}{l}\text { D: TE } \\
(\mathrm{mA})\end{array}$ & $\begin{array}{c}\text { E: Error } \\
\text { E = D/A }(\%)\end{array}$ & $\begin{array}{l}\text { F: TE } \\
(\mathrm{mA})\end{array}$ & $\begin{array}{c}\text { G: Error } \\
\text { G = F/A ( } \%)\end{array}$ \\
\hline 0.01 & 13.36 & 133.600 & 5.49 & 54.900 & 1.46 & 14.600 \\
\hline 0.30 & 6.78 & 2.260 & 5.43 & 1.810 & 0.87 & 0.290 \\
\hline 0.50 & 3.77 & 0.754 & 2.36 & 0.472 & 0.56 & 0.112 \\
\hline 0.80 & 1.72 & 0.215 & 5.36 & 0.670 & 0.11 & 0.014 \\
\hline 1.00 & 0.30 & 0.030 & 1.41 & 0.140 & 0.79 & 0.079 \\
\hline 1.50 & 5.21 & 0.347 & 3.29 & 0.219 & 1.86 & 0.124 \\
\hline
\end{tabular}

Note: TE is the abbreviation of "tracking error". TE is the error between the desired current and the actual output current in RMS sense.

Table 3. Peak-to-peak amplitudes of current ripples.

\begin{tabular}{|c|c|c|c|c|c|}
\hline Amplitude of $i_{A M B}(\mathrm{~A})$ & $\begin{array}{c}\text { Two-State PA (DDM) } \\
\begin{array}{c}\text { A: PPACR } \\
\text { (mA) }\end{array}\end{array}$ & \multicolumn{2}{|c|}{ Three-State PA } & \multicolumn{2}{|c|}{$\mathrm{DC}^{2}$} \\
\hline 0.30 & 30.5 & 4.6 & $84.92 \%$ & 3.4 & $88.85 \%$ \\
\hline 0.50 & 30.0 & 5.5 & $81.67 \%$ & 4.2 & $86.00 \%$ \\
\hline 0.80 & 29.3 & 5.8 & $80.20 \%$ & 5.2 & $82.25 \%$ \\
\hline 1.50 & 27.7 & 7.5 & $72.92 \%$ & 7.2 & $74.01 \%$ \\
\hline
\end{tabular}

Note: 1. "PPACR" is the abbreviation of "peak-to-peak amplitude of current ripple"; 2 . "Imp." is the abbreviation of "improvement". 
Table 4. Power dissipation at MOSFETs.

\begin{tabular}{|c|c|c|c|c|c|}
\hline \multirow{2}{*}{ Amplitude of $i_{A M B}(\mathrm{~A})$} & \multirow{2}{*}{$\begin{array}{c}\text { Two-State PA (DDM) } \\
\text { A: PD } \\
(\mathrm{mW})\end{array}$} & \multicolumn{2}{|c|}{ Three-State PA } & \multicolumn{2}{|c|}{$\mathrm{DC}^{2}$} \\
\hline & & $\begin{array}{l}\text { B: PD } \\
\text { (mW) }\end{array}$ & $\begin{array}{c}C: \text { Imp. } \\
C=(A-B) / A\end{array}$ & $\begin{array}{l}\text { D: PD } \\
\text { (mW) }\end{array}$ & $\begin{array}{c}E: \operatorname{Imp.} \\
E=(A-D) / A\end{array}$ \\
\hline 0.01 & 0.02 & $<0.01$ & $95.59 \%$ & $<0.01$ & $96.80 \%$ \\
\hline 0.30 & 3.93 & 0.50 & $87.28 \%$ & 0.84 & $78.63 \%$ \\
\hline 0.50 & 10.99 & 1.68 & $84.71 \%$ & 2.65 & $75.89 \%$ \\
\hline 0.80 & 28.42 & 6.09 & $78.57 \%$ & 8.15 & $71.32 \%$ \\
\hline 1.00 & 44.69 & 11.20 & $74.94 \%$ & 14.08 & $68.49 \%$ \\
\hline 1.50 & 102.06 & 32.76 & $69.90 \%$ & 39.69 & $61.11 \%$ \\
\hline
\end{tabular}

Note: 1. "PD" is the abbreviation of "power dissipation". 2. "Imp." is the abbreviation of "improvement".

The simulation results to track the sinusoidal wave by two-state power amplifier (PA), three-state PA and DC ${ }^{2}$ are shown in Figures 10 and 11. The reference signal in Figure 10 is a sinusoidal wave with $50 \mathrm{~Hz}$ and amplitude $0.7 \mathrm{~A}$ while the reference signal in Figure 11 is a sinusoidal wave with $500 \mathrm{~Hz}$ amplitude $0.1 \mathrm{~A}$. It is noted that the current ripples are almost eliminated by $\mathrm{DC}^{2}$ (see Figures $10 \mathrm{i}$ and 11ii). On the other hand, the tracking errors and the current ripples by $\mathrm{DC}^{2}$ are very close to those by the three-state PA either for low-speed case or for high-speed case. To sum up, the performance to track a sinusoidal wave by $\mathrm{DC}^{2}$ is superior to that by the three-state PA.

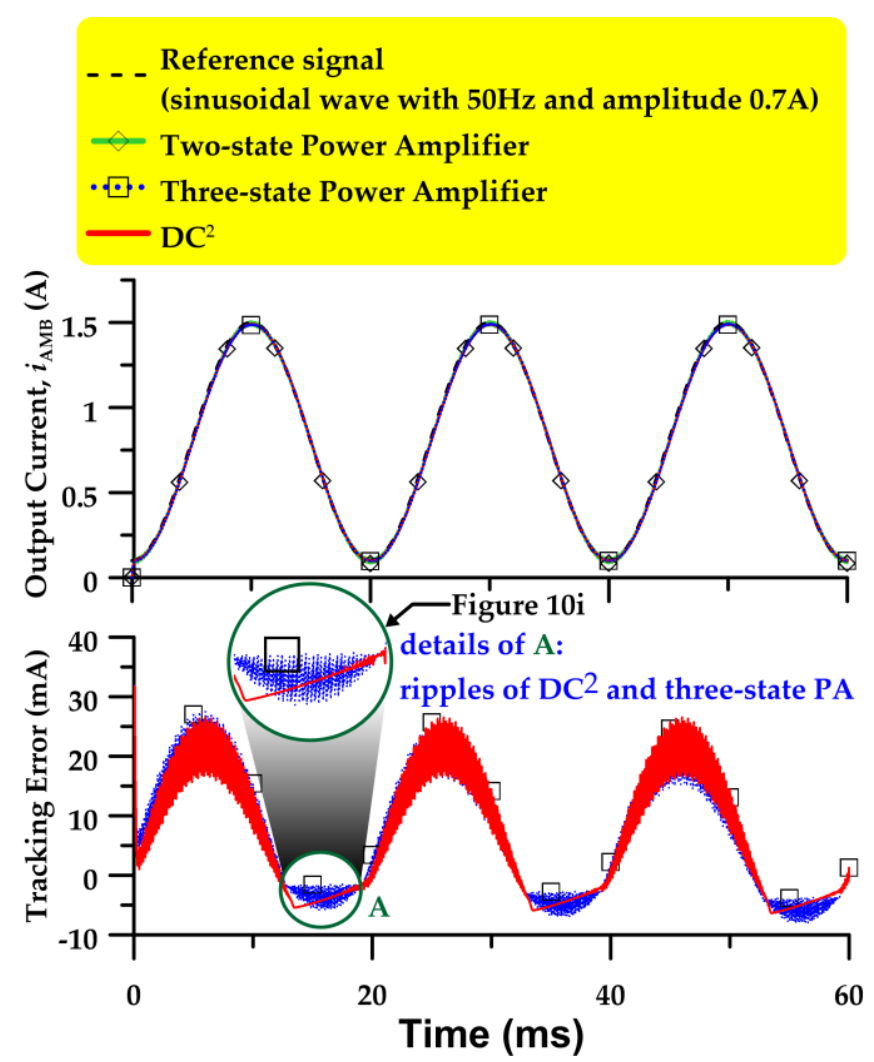

Figure 10. Output currents and tracking errors by two-state power amplifier, three-state power amplifier and $\mathrm{DC}^{2}$ (dual cooperative drive circuit). (Reference signal: sinusoidal wave with $50 \mathrm{~Hz}$ and amplitude $0.7 \mathrm{~A})$. 


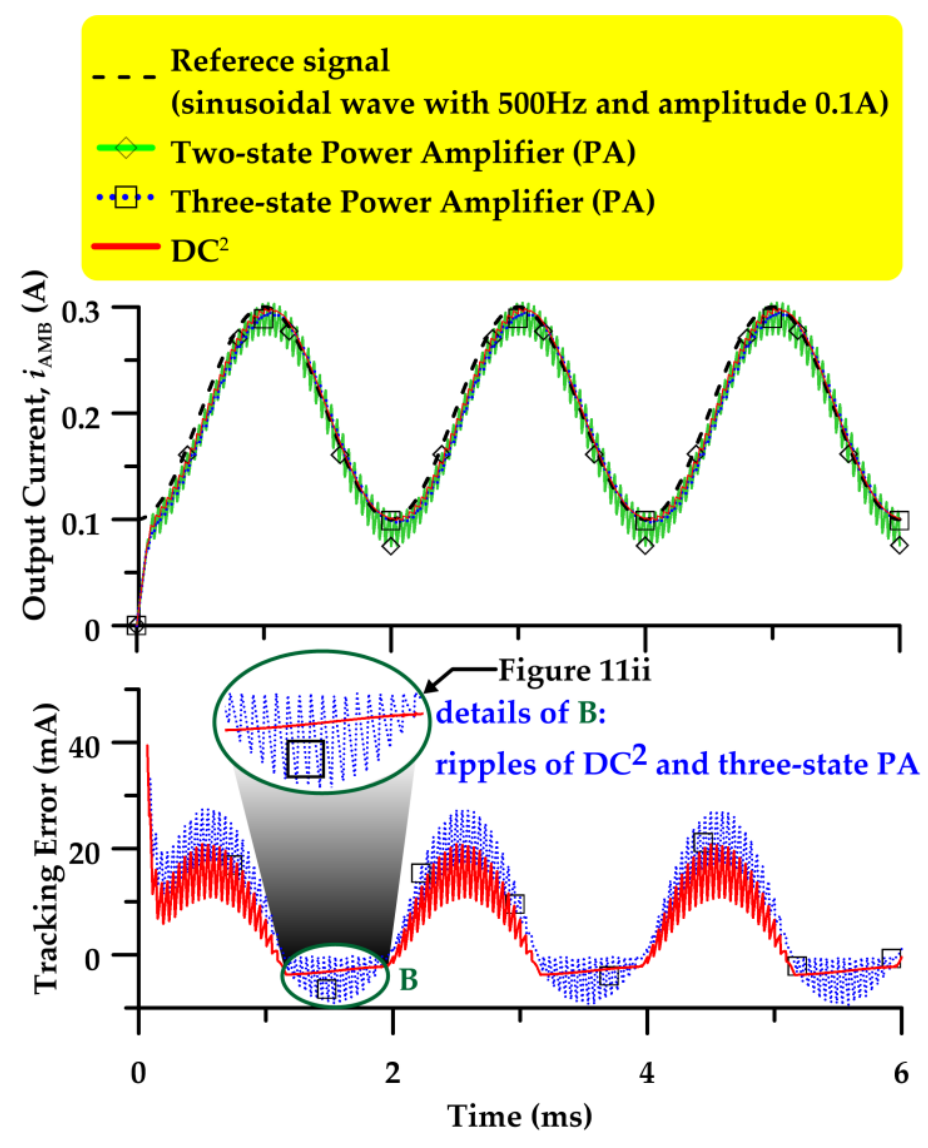

Figure 11. Output currents and tracking errors by two-state power amplifier, three-state power amplifier and $\mathrm{DC}^{2}$ (dual cooperative drive circuit). (Reference signal: sinusoidal wave with $500 \mathrm{~Hz}$ and amplitude $0.1 \mathrm{~A})$.

\section{Experiments}

In this section, a few experiments are undertaken to examine the feasibility and capability of the proposed $\mathrm{DC}^{2}$ in terms of tracking capability and ripple suppression. The photographs and the corresponding layout of $\mathrm{DC}^{2}$ are shown in Figure 12. Besides, the experimental test rig, shown in Figure 13, is constructed. The schematic diagram of equipped facilities to conduct the corresponding experiments is depicted in Figure 14. The load to drive, with respect to $D C^{2}$, is any one of the axial AMBs of the 5-DOF rotor/active magnetic bearing (Rotor/AMB) unit. The electrical resistance and the nominal inductance of this AMB coil are $0.9 \Omega$ and $7 \mathrm{mH}$ respectively. Two sets of direct current (DC) power supplies are employed. The first set, ITech IT6332A, is employed to provide +5 VDC / +15 VDC for $\mathrm{DC}^{2}$. The other set, Keithley 2268-40-21, is applied to drive the AMB coils by +40 VDC. The DSP chip, Texas Instruments TMS320F28335, in which the PWM-TPs are embedded, receives the signal from the CS (Current Sensor), $\hat{u}_{A M B}$, and then generates the two control commands, i.e., $P W M \# \mathbf{1}$ and $P W M \# 2$, to $D^{2}$. 


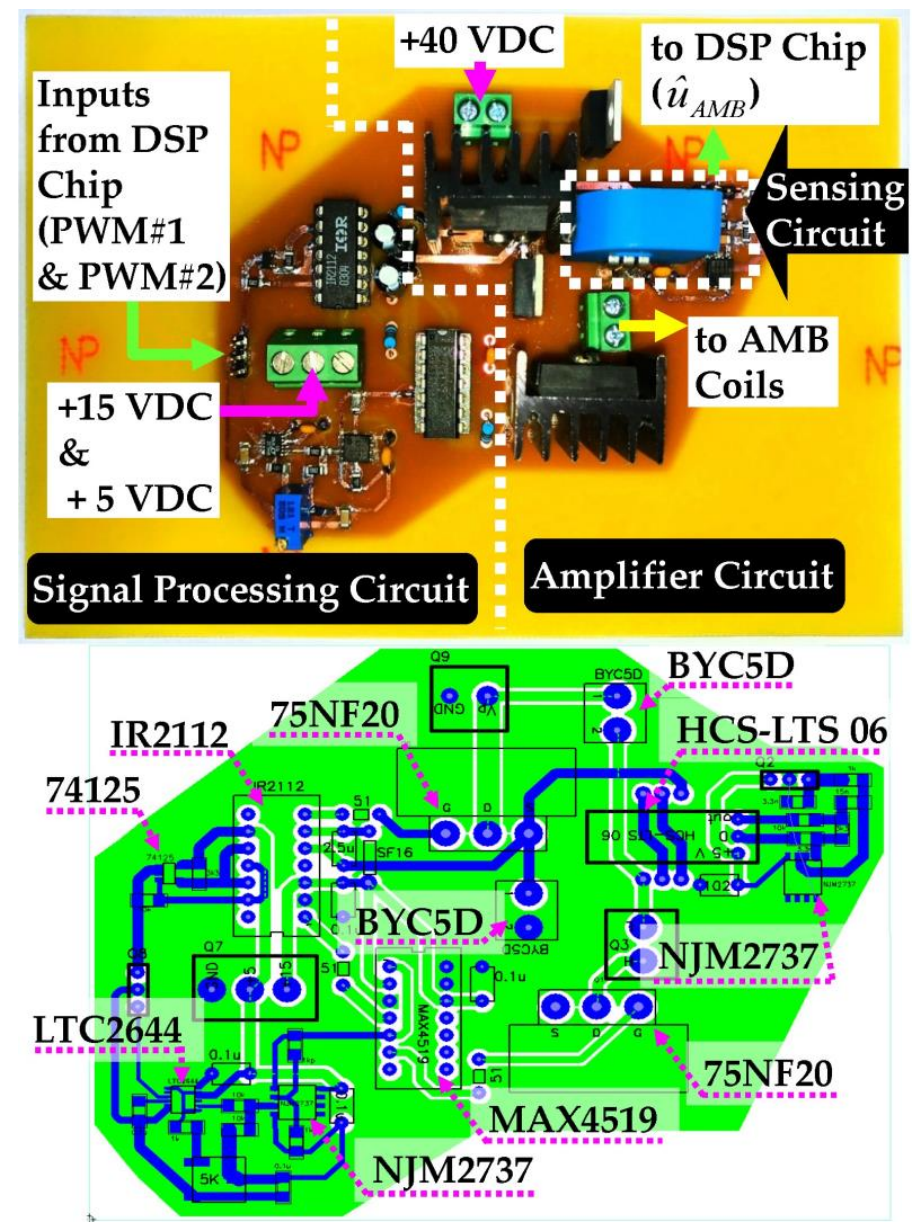

Figure 12. Photograph and layout of dual cooperative drive circuit $\left(\mathrm{DC}^{2}\right)$.

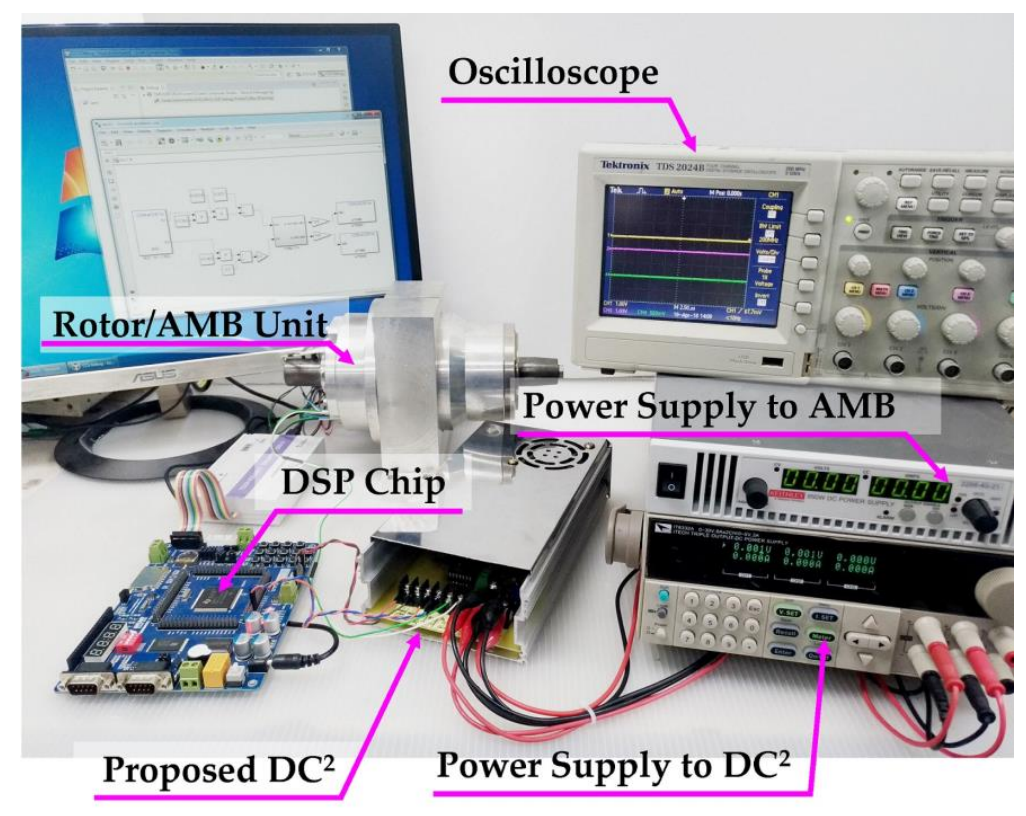

Figure 13. Experimental setup. 


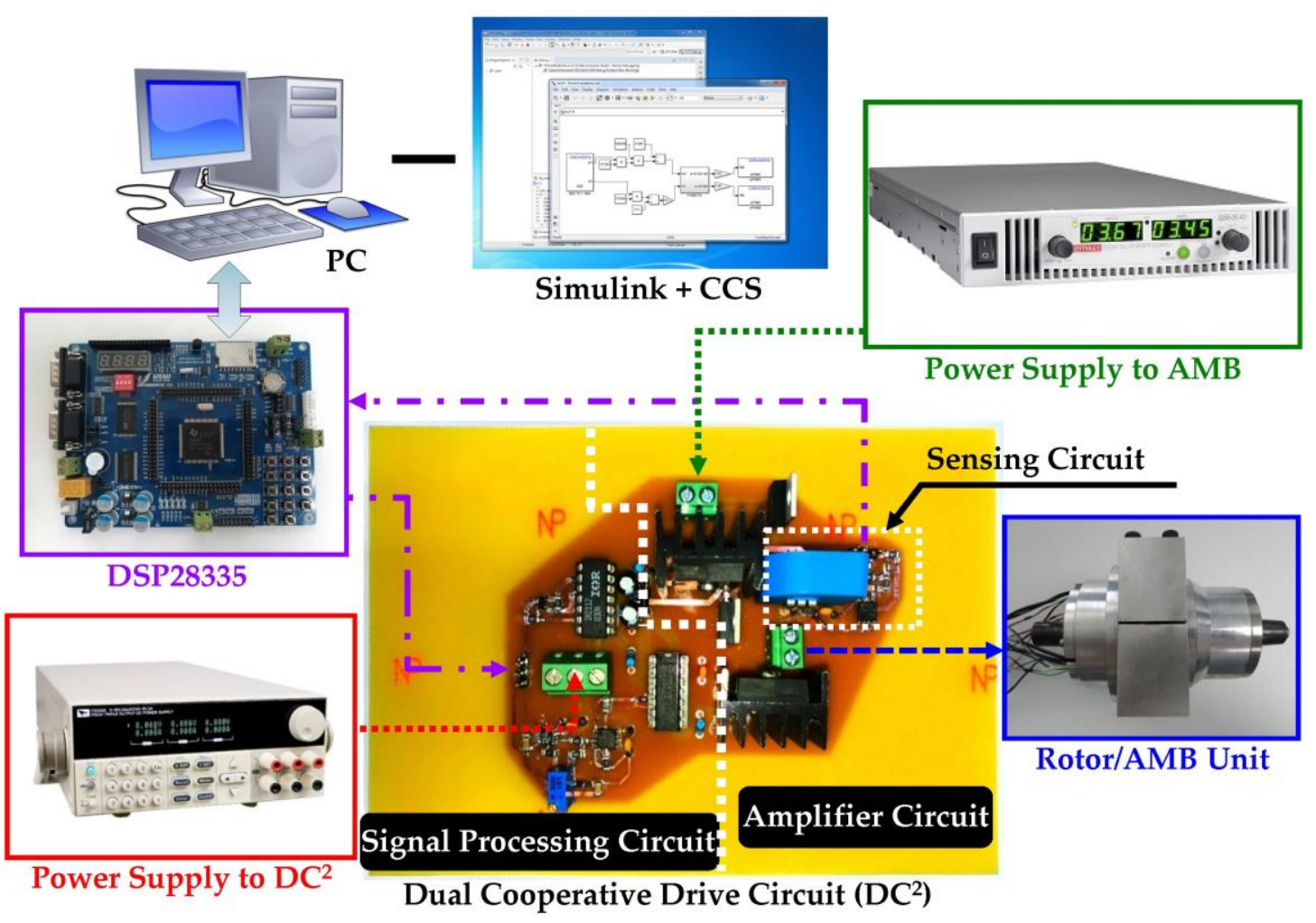

Figure 14. Schematic diagram of equipped facilities to conduct experiments.

For the experiments undertaken, the desired output, a sequence of step-wise reference, is preset at the DSP chip. The amplitude and the duty ratio of the step-wise reference are set as $1 \mathrm{~A}$ and $50 \%$ respectively. The tracking performances under $\mathrm{DC}^{2}, \mathrm{DDM}$ and ADM are shown in Figure 15. From Figure 15, it is observed that at the beginning of tracking the step-wise signal, i.e., starting $2.5 \mathrm{~ms}$ to $2.8 \mathrm{~ms}$, the $\mathrm{DC}^{2}$ operates by DDM. Under DDM, the duty ratio of $P W M \# \mathbf{1}$ (with respect to the Observation Point $O P \# 1$ ) is adjusted to its maximum, i.e., $95 \%$, so that the output current is able to track the desired output as fast as possible. This is the major advantage of DDM at transient state of the rotor position regulation dynamics. However, $M \# \mathbf{1}$ and $\mathbf{M} \# \mathbf{2}$ operate both in on-off fashion synchronously under DDM which unfortunately induces severe current ripples embedded in the output current. In comparison, unlike the digital control command to $\mathbf{M} \# \mathbf{2}$ under DDM (with respect to $O P \# 2^{\prime}$ ), the control command to $\mathbf{M \# 2}$ under ADM (with respect to $O P \# 2$ ) is in analog manner. Accordingly, as soon as the output current to the axial AMB coil gets close to the desired quantity, $\mathrm{DC}^{2}$ is switched to ADM. As $\mathrm{DC}^{2}$ is switched from DDM to ADM, the mechanism of $\mathbf{M} \# \mathbf{2}$, which is in on-off fashion under DDM, is changed to the voltage-controlled fashion to refine the output current more precisely. In addition, at steady state of the rotor position regulation dynamics, compared with

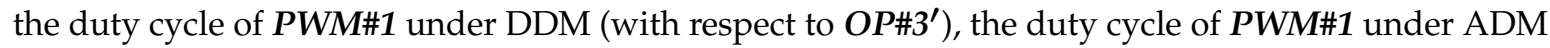
(with respect to $O P \# 3$ ) is reduced to a relatively low degree. As a result, the fluctuation of output

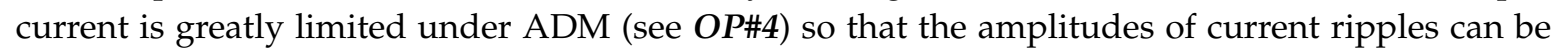
certainly much reduced. 


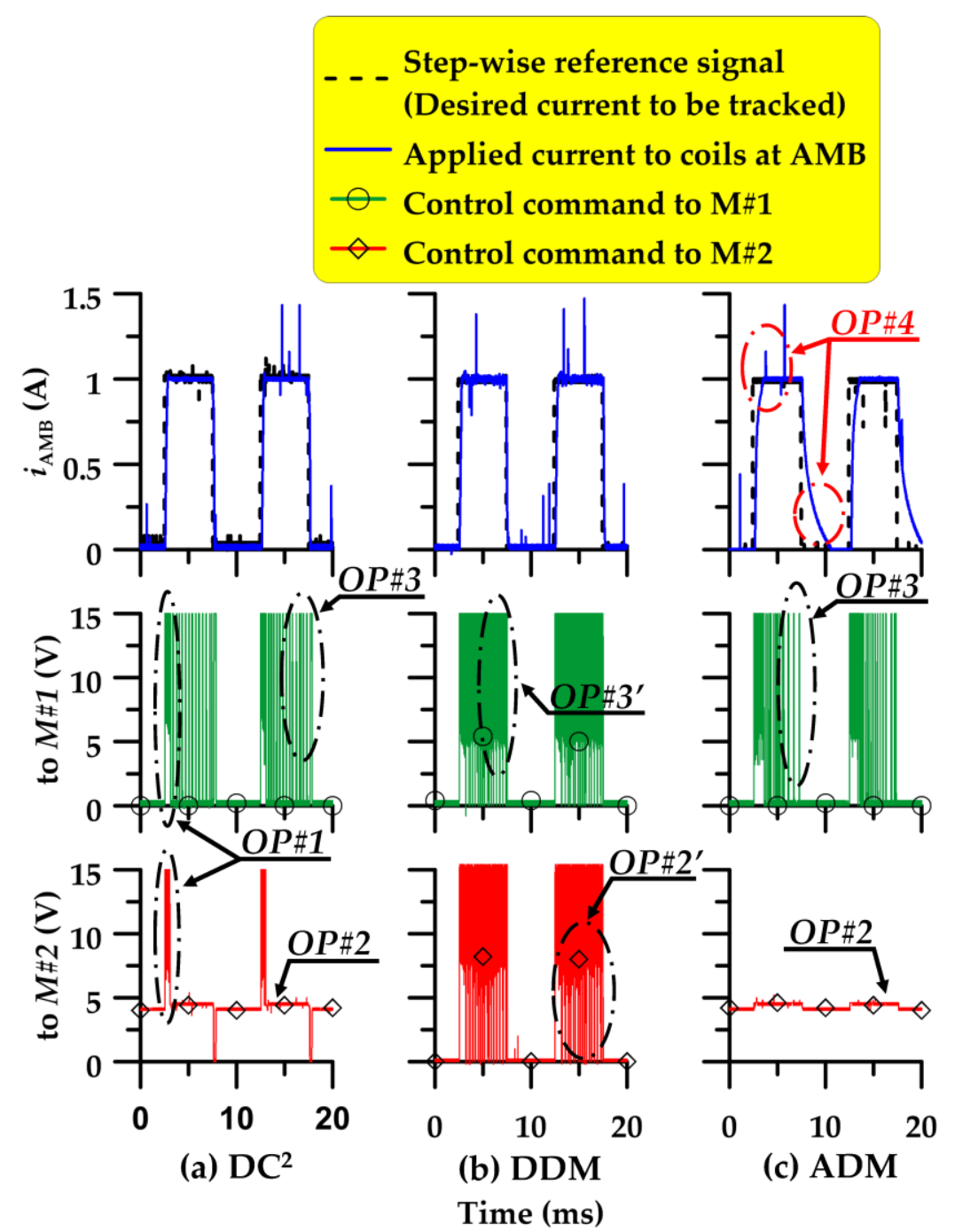

Figure 15. Experimental results: (a) under $\mathrm{DC}^{2}$ (dual cooperative drive circuit); (b) under DDM (digital driving mode); (c) under ADM (analog driving mode).

To be explicitly compared, the corresponding tracking performances under DDM, ADM and $\mathrm{DC}^{2}$ are depicted by Figure 16. It is observed that the rise time under ADM, i.e., $1.08 \mathrm{~ms}$ from $A_{0}$ to $A^{\prime}$, is much longer than that under DDM or $\mathrm{DC}^{2}$, i.e., $0.40 \mathrm{~ms}$ from $A_{0}$ to $A$. That is, the response of ADM is relatively slow so that ADM is inappropriate to be applied at transient state. On the other hand, the amplitude of the peak-to-peak current ripples under DDM is about $50 \mathrm{~mA}$ while it is merely $19 \mathrm{~mA}$ under either $\mathrm{ADM}$ or $\mathrm{DC}^{2}$. That is, the improvement degree of reducing the peak-to-peak amplitude of current ripples by $\mathrm{DC}^{2}$ is about $62 \%$. This also implies that DDM is inappropriate to be applied at steady state. In comparison to DDM, $\mathrm{DC}^{2}$ additionally possesses the merit of significantly limited current ripples. To sum up, $\mathrm{DC}^{2}$ can provide a relatively stable current to drive $\mathrm{AMB}$ coils with a much shorter rise time and relatively minor ripples. 


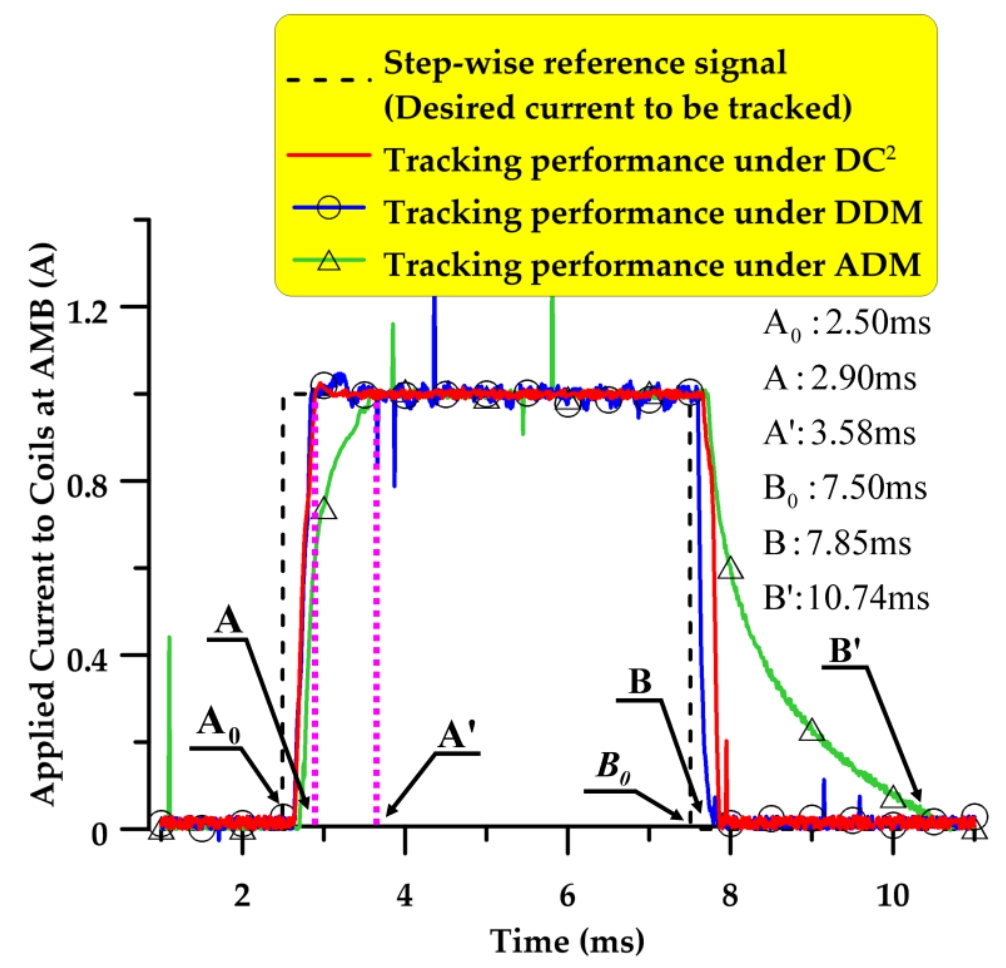

Figure 16. Tracking performances of $i_{A M B}$ under DDM (digital driving mode), ADM (analog driving mode) and $\mathrm{DC}^{2}$ (dual cooperative drive circuit).

\section{Conclusions}

A novel compact hybrid power amplifier applied for active magnetic bearings (AMBs), named as dual cooperative drive circuit $\left(\mathrm{DC}^{2}\right)$, is proposed and verified by intensive simulations and experiments. $\mathrm{DC}^{2}$ can conduct under any of the two operation modes: digital driving mode (DDM) and analog driving mode (ADM). As the rotor / AMB dynamics is at transient state, $\mathrm{DC}^{2}$ operates under DDM to provide quick energization to $\mathrm{AMBs}$ by higher current slew rate. On the other hand, as the rotor/AMB dynamics is at steady state, $\mathrm{DC}^{2}$ operates under ADM to provide an output current with relatively mild current ripples so that the steady state of the rotor can be well-retained, without significant reciprocated fluctuation away from the neutral position. It is noted that all the signals fed to $\mathrm{DC}^{2}$ are of pulse width modulation (PWM) fashion. As a matter of fact, $\mathrm{DC}^{2}$ can be directly driven by a digital signal processing (DSP) chip. From the experimental results, compared to a traditional two-level power amplifier, the improvement degree of reducing the amplitudes of peak-to-peak current ripples is up to $62 \%$ by $D C^{2}$. From the viewpoint of response, the rise time by $D^{2}$ is much shorter than that under ADM. By taking advantages of complementary cooperation between DDM and ADM, the proposed $\mathrm{DC}^{2}$ manifests its superiorities on both high current slew rate, low tracking error, and significantly suppressed current ripples.

Author Contributions: H.-L.C. undertakes the experiments and analyzes the data. N.-C.T. designs the structure of research, contributes to the discussion, and revises the manuscript.

Funding: This research was partially supported by Ministry of Science and Technology (Taiwan) with a 3-year Grant MOST 105-2221-E-006-070-MY3.

Acknowledgments: The authors would like to express their appreciations to Ministry of Science and Technology (Taiwan).

Conflicts of Interest: The authors declare no conflicts of interest. 


\section{List of Abbreviations}

$\begin{array}{ll}\text { ADM } & \text { Analog Driving Mode } \\ \text { AMB } & \text { Active Magnetic Bearing } \\ \text { CS } & \text { Current Sensor } \\ \text { DAC } & \text { Digital to Analog Converter } \\ \text { DC } & \text { Direct Current } \\ \text { DC } & \text { Dual Cooperative Drive Circuit } \\ \text { DDM } & \text { Digital Driving Mode } \\ \text { DSP } & \text { Digital Signal Processor } \\ \text { EMI } & \text { Electromagnetic Interference } \\ \text { Imp. } & \text { Improvement } \\ \text { IC } & \text { Integrated Circuit } \\ \text { LPF } & \text { Low Pass Filter } \\ \text { MUX } & \text { Multiplexer } \\ \text { MOSFET } & \text { Metal-Oxide-Semiconductor Field-Effect Transistor } \\ \text { OP } & \text { Observation Point } \\ \text { PA } & \text { Power Amplifier } \\ \text { PD } & \text { Power Dissipation } \\ \text { PI } & \text { Proportional-Integral } \\ \text { PID } & \text { Proportional-Integral-Derivative } \\ \text { PPACR } & \text { Peak-to-Peak Amplitude of Current Ripple } \\ \text { PWM } & \text { Pulse Width Modulation } \\ \text { PWM-TP } & \text { Pulse Width Modulation-Tuning Processor } \\ \text { SLH } & \text { Switch-Linear Hybrid } \\ \text { TE } & \text { Tracking Error } \\ & \end{array}$

\section{References}

1. Carabelli, S.; Muzzarelli, M. High-efficiency linear power amplifier for active magnetic bearings. IEEE Trans. Ind. Electron. 2000, 47, 17-24. [CrossRef]

2. Cerruti, F.; Delprete, C.; Genta, G.; Carabelli, S. High efficiency and low cost power amplifiers and transducers for active magnetic bearings. In Proceedings of the Fourth International Symposium on Magnetic Bearings, Zurich, Switzerland, 23-26 August 1994.

3. Ren, Y.; Fang, J. Current-sensing resistor design to include current derivative in pwm h-bridge unipolar switching power amplifiers for magnetic bearings. IEEE Trans. Ind. Electron. 2012, 59, 4590-4600. [CrossRef]

4. Schulz, A.; Wassermann, J.; Schneeberger, M. A reliable switching amplifier for active magnetic bearings. In Proceedings of the IEEE International Conference on Industrial Technology, Maribor, Slovenia, 10-12 December 2003.

5. Cao, G.; Lee, C.W. Development of PWM power amplifier for active magnetic bearings. In Proceedings of the Fifth World Congress on Intelligent Control and Automation, Hangzhou, China, 15-19 June 2004.

6. Yoshida, T.; Kuroba, Y.; Ohniwa, K.; Osamu, M. Self-sensing active magnetic bearings using a new PWM amplifier equipped with a bias voltage source. Eur. Power Electron. Drives 2005, 15, 19-24. [CrossRef]

7. Zhu, C.; Mao, Z. A PWM based switching power amplifier for active magnetic bearings. In Proceedings of the Eighth International Conference on Electrical Machines and Systems, Nanjing, China, 27-29 September 2005.

8. Zhang, J.; Karrer, N. IGBT power amplifiers for active magnetic bearings of high speed milling spindles. In Proceedings of the 21st International Conference on Industrial Electronics, Control, and Instrumentation, Orlando, FL, USA, 6-10 November 1995.

9. Wang, J.; Wang, L.; Dong, J.; Juang, C. Research on the steady state and ripple current models of current mode switching power amplifier for magnetic bearing. J. Softw. Eng. 2015, 9, 157-168. [CrossRef]

10. Kashiwagi, S. A high-efficiency audio power amplifier using a self-oscillating switching regulator. IEEE Trans. Ind. Appl. 1985, IA-21, 906-911. [CrossRef]

11. Jin, Q.; Ruan, X.; Ren, X.; Xi, H. High-efficiency switch-linear-hybrid envelope-tracking power supply with step-wave approach. IEEE Trans. Ind. Electron. 2015, 62, 5411-5421. [CrossRef] 
12. Jin, Q.; Ruan, X.; Ren, X.; Wang, Y.; Leng, Y.; Tse, C.K. Series-parallel-form switch-linear hybrid envelope-tracking power supply to achieve high efficiency. IEEE Trans. Ind. Electron. 2017, 64, $244-252$. [CrossRef]

13. Wang, Y.; Jin, Q.; Ruan, X. Optimized design of the multilevel converter in series-form switch-linear hybrid envelope-tracking power supply. IEEE Trans. Ind. Electron. 2016, 63, 5451-5460. [CrossRef]

14. Silva, G.S.; Beltrame, R.C.; Schuch, L.; Rech, C. Hybrid AC power source based on modular multilevel converter and linear amplifier. IEEE Trans. Power Electron. 2015, 30, 216-226. [CrossRef]

15. Tsai, N.C.; Kuo, C.H.; Lee, R.M. Regulation on radial position deviation for vertical AMB systems. Mech. Syst. Signal Process. 2007, 21, 2777-2793. [CrossRef]

16. Tsai, N.C.; Chiang, C.W.; Li, H.Y. Innovative active magnetic bearing design to reduce cost and energy consumption. Electromagnetic 2009, 29, 406-420. [CrossRef]

17. Tsai, N.C.; Lee, R.M. Regulation of spindle position by magnetic actuator array. Int. J. Adv. Manuf. Technol. 2011, 53, 93-104. [CrossRef]

18. Tracxler, A.; Malsen, E. Hardware Components. In Magnetic Bearings: Theory, Design, and Application to Rotating Machinery, 1st ed.; Schweitzer, G., Maslen, E.H., Eds.; Springer: London, UK; New York, NY, USA, 2009; p. 98, ISBN 978-3-642-00496-4.

19. MAXIM Integrated Products. Reliability Report for MAX4518ESD+; MAXIM Integrated Products: San Jose, CA, USA, 2010.

20. Linear Technology. Reliability Data Report: Product Family R461; Linear Technology: Milpitas, CA, USA, 2015.

(C) 2018 by the authors. Licensee MDPI, Basel, Switzerland. This article is an open access article distributed under the terms and conditions of the Creative Commons Attribution (CC BY) license (http://creativecommons.org/licenses/by/4.0/). 